\title{
Influence of Family Status on the Dietary Patterns and Nutritional Levels of Children
}

\section{R. M. Kapila Tharanga Rathnayaka*, Zhong-Jun Wang}

Department of Statistic, Science Collage, Wuhan University of Technology, Wuhan, China.

Email: *kapila.tr@gamil.com

Received May $8^{\text {th }}$, 2012; revised June $15^{\text {th }}, 2012$; accepted June $22^{\text {nd }}, 2012$

\begin{abstract}
A diversity of socio economic and cultural factors contributes towards maintenance and changes in dietary patterns of people. Therefore People around the world have adapted different types of dietary patterns for their survival. Aim of this study was to investigate the most relevant factors influencing human dietary patterns. Sample for the study was selected by using the Stratified sampling technique, which consists of 390 families residing around the Abatenna estate, Bandarawela municipal council, Sri Lanka. Principal component analysis techniques and correlation analysis were employed to identify the most relevant factors which affect human dietary patterns. Results of the study indicate that socio economic conditions, monthly income, number of children in a family, dietary patterns and weight-related behaviors are highly co-related with each other. These findings suggest that education and awareness programs on nutrition should target low income groups to enhance their knowledge on dietary patterns.
\end{abstract}

Keywords: Principal Component Analysis; Nutritional Level; Dietary Pattern; Weight-Related Behaviors

\section{Introduction}

Humans are subsisting on products of plant and animal origins as their food. Food is the most important basic necessity for human beings other than water and oxygen. Body cells are dependent on the intake of food for the supply of nutrients such as Carbohydrates, Proteins, Fat, Vitamins, Minerals and Fiber. Therefore intake of a balanced diet is of paramount importance for an optimal supply of nutrition to human beings. People have different nutritional requirements, for an example, Children and pregnant women require different levels/patterns of nutrition in comparison to the elderly. Therefore, during the past few decades, many researchers worldwide have focused considerable attention on finding out relations between human diets and nutrition levels.

Due to a variety of social, economic and cultural factors, dietary patterns and eating habits differ from person to person as well as country to country. People from different regions consume different kinds of food prepared in a variety of ways [1]. For an example: Japanese are synonymous with Sushi, while fish and chips are associated with British, and tacos and nachos are conjuring up images of Mexico etc. Different kinds of food symbolize unique characteristics of different societies and their cultural heritage [2].

"Corresponding author.
However, the diet and what people desire to eat is decided by many factors, such as: family income, time and resources they have and others [3]. Parents are always vigilant and concerned about eating habits and nutritional levels of their children. Therefore this study is designed to determine the relations and effect of family income and parent's status on children's dietary habits and weighted-related behaviors. This survey was conducted among 390 families with different type of socio-economical conditions, who are living around the Abatenna estate, Bandarwela municipal council, Badulla district, Sri Lanka.

Stratified sampling techniques were used to select the survey sample. Clear instructions were given to parents regarding the study and a well-structured questionnaire was distributed among them. Answer sheets were collected after one week. Principal component analysis was used to identify the relations between expenditure on diet and other co-related factors.

\section{Review of Related Literature}

Several studies have been carried out by numerous researchers from different countries based on human dietary patterns. In 2008, Catherine and co-workers conducted a research based on parents serve as role models in influencing children's weighted behaviors [4]. Samples were collected from four child care centers near 
Southeastern University in USA Correlation analysis has been briefly discussed with experimental results. Kandiah and group have done several research works to identify food preference factors of children. Based on their analysis, parents influence is the most critical factor for eating habits of their children. Moreover, they concluded that restrictions on food habits by parents were counter-productive and contradicted with eating abilities of children [5].

According to the literature, so many studies have been done to determine the relations between individual precision of food intake regulation and children's anthropometric measures. In 2006, Craeynest and group carried out research work based on this problem. Sixty overweight and less control groups of children were selected as experimental and control groups [6]. Food Habits, food preferences and their weight gauge were compared at the start and end of the study. The results were coincided with Golan et al. findings in 1996 under the topic of "Parents as the exclusive agents of change in the treatment of childhood obesity" [7].

Brown et al. reported a new methodology and control theories for parental pressure on eating habits of their children, using various factors such as parent and children snack intake, eating motivations and weight related factors [8]. By using correlation and co-variance analysis, Heck and his group have identified several effective food preference factors for children's diet. According to their suggestions, parent modeling of food intake, home environment and food availability, parent's attitudes, habits and presumption and family income are the main factors which effects eating habits of children [9].

Hood and co-workers used general linear regression model to identify the dietary habits while publish their findings under the title "Parental eating attitudes and the development of obesity in children" [10]. This approach has been successfully applied for the 1987 Framingham Children's Study. Data were collected through a structured questionnaire. According to the survey results, parental dietary restraint and disinhibition are main factors that may strongly influence child's early eating experiences.

\section{Materials and Methods}

\section{Study Area and Data Collection}

The study was carried out around Abatenna estate, Bandarawela Municipal council and Badulla province of Sri Lanka. Bandarawela is located on the central hills of the island and surrounded by beautiful tea plantains [11].

Approximately six hundred families live in Abatenna estate, representing different ethnic groups such as Sinhala, Tamil, Muslim, Malay, and Burgers. Majority of them are directly involved in government or private sec- tors jobs.

With the aim of unbiased conclusions, variety of families (teachers, doctors, lawyers, managers, businessmen and workers) representing a widespread of socio-economical conditions were selected as the sample. Under the stratified sampling assumptions, families were categorized in to sub populations based on family income and family norm using Bandarawela municipal council annual reports. A unique identification number was assigned to each family individually, for the ease of conduct of the survey.

Structured questionnaires were distributed to the selected sample families to gather information such as their occupation, Socio-economic status, living environment, family norm, and average monthly expenditure on food. Also we have measured their height $(\mathrm{cm})$ and body weight $(\mathrm{kg})$ individually for calculate Body mass index (BMI). BMI calculated by using following formula [12].

$$
\text { BMI }=\frac{\text { Weight }(\mathrm{kg})}{\text { Height }(\mathrm{m})^{2}}
$$

BMI levels below 18.5 is considered as underweight and Levels between 18.5 - 24.9 considered as normal weight and BMI between 25 - 29 categorized as overweight and others as obsess.

The questionnaire was compiled in both Sinhala and Tamil languages (the two major languages spoken in Sri Lanka) to avoid language differences. The questionnaires were distributed during November 2011 to December 2011. Completed questionnaires were collected twice a week.

\section{Results and Discussion}

Data collected through questionnaires were entered in to Microsoft Excel data base and analyzed using Minitab and SPSS statistical software packages. Principal component analysis techniques along with factor analysis methods were utilized to identify the factors affecting the family nutrition levels. Results were discussed under the 0.05 level of significance.

\subsection{Analysis of Factors Influencing Human Dietary Patterns}

Personal information on socio-economic status such as their monthly income, educational level, parent's occupation and number of children in a family and were obtained using questionnaires.

Purpose of this study was to determine whether income and occupation of parents has an influence on the nutritional level of their children.

As the first step, families were categorized into groups considering two main factors. First categorization was based on monthly income (A-more than RS 40,000, B-Rs, 
10,000 - 39,999, C-less than 10,000) and the second categorization was based on number of Children in a family (Figure 1).

Majority were under group B (49\%) and others, 23\% and $28 \%$ in group $\mathrm{A}$ and $\mathrm{C}$ respectively. Majority of the people in group $\mathrm{A}$ and $\mathrm{B}$ are educated and engaged in high-ranking jobs such as doctors, lawyers and teachers. However, social and economic statuses of the inhabitants in group $\mathrm{C}$ are relatively low compared to others.

\subsubsection{Correlation Analysis}

Pearson correlation coefficients were computed for find the relations between family income; parent's occupation; family norm; nutrition levels of their diet within our survey period. Vegetables, fruits, bread, milk, butter, meat, fish and junk food weekly intake was considered for evaluate nutrition levels.

According to findings of the study, a significant correlation exists between income level and nutrition level of the diet of their children. Because, monthly income ( $r=$ 0.843, $p=0.003)$ and parent's job status $(r=0.746, p=$ 0.002 ) was closely related with the consumption of meat, fish and junk food in their diet per week.

Table 1 results indicate that the parent's job status and their eating habits directly affect for their children nutrition levels. However, meat, fish and butter intakes are highly and positively co-related with monthly income and BMI levels. The results show that the nutrition levels of individuals are positively associated with the parent's monthly income.

Principal component methods are one of the most suitable methods for interpretation of correlations between original variables.

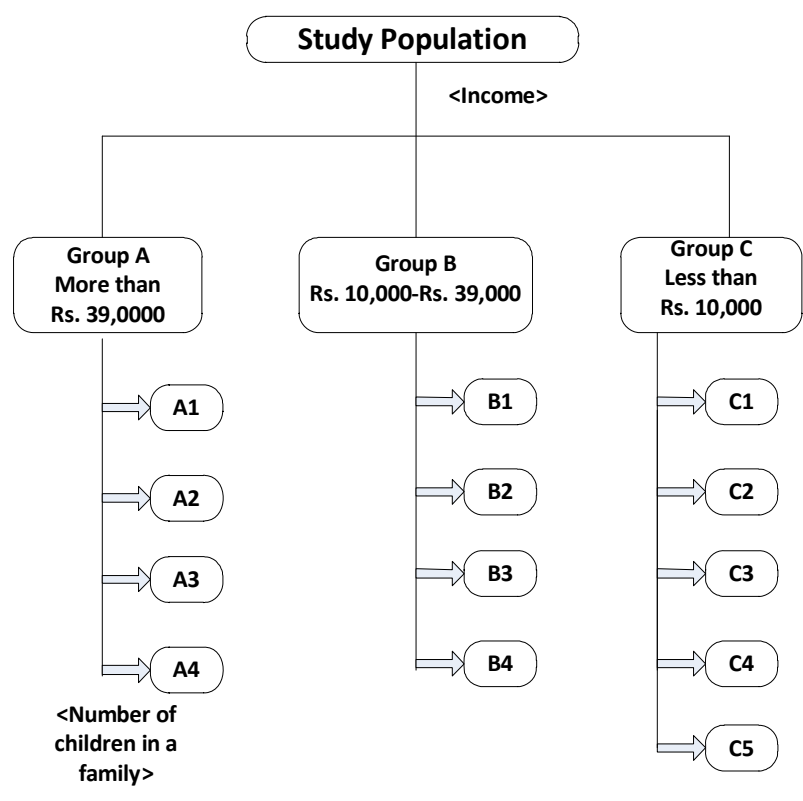

Figure 1. Sampling structure.
According to the cumulative proportions in Table 2, first two principal components (PC) explain $87.7 \%$ of the variables [13].

In Figure 2, data points clearly (with a slight deformation by the higher income family) show that families with higher expenditures (higher number of children) are on the left.

\subsubsection{ANOVA Analysis for Weighted Related Behaviors}

One way analysis of variance method used for compare the individuals weighted related behaviors and their family income. According to the ANOVA results, Families of group A are characterized by higher expenditures on vegetables, meat, butter, milk and Cheese ( $F=10.753$ and $p=0.001)$. However, vegetables and bread expenditures are similar for three groups $(\mathrm{F}=1.142$ and $p=$ 0.104).

\section{Conclusion}

Parents continually think about their children when they make decisions on health and nutrition. This research briefly targets on determining the most suitable factors which influence on family nutrition levels. Heterogeneous samples were selected under the factors such as monthly income and family norm.

The major finding of this study is that the status of parents and their monthly income were inversely related to family nutrition levels. Children of group $\mathrm{A}$ and $\mathrm{B}$ (monthly income $>10,000$ ) had a higher mean score on per week serving of meat, fish, junk foods, milk and butter, compared with group C.

Nutritious food plays a significant role in maintaining a healthy body which is compatible with long life. Food can be categorized in to five major groups like proteins, fats, carbohydrates, mineral and water [14]. Human body needs varying amount of these types for daily activities. Nutritients are obligatory in order to build and repair the

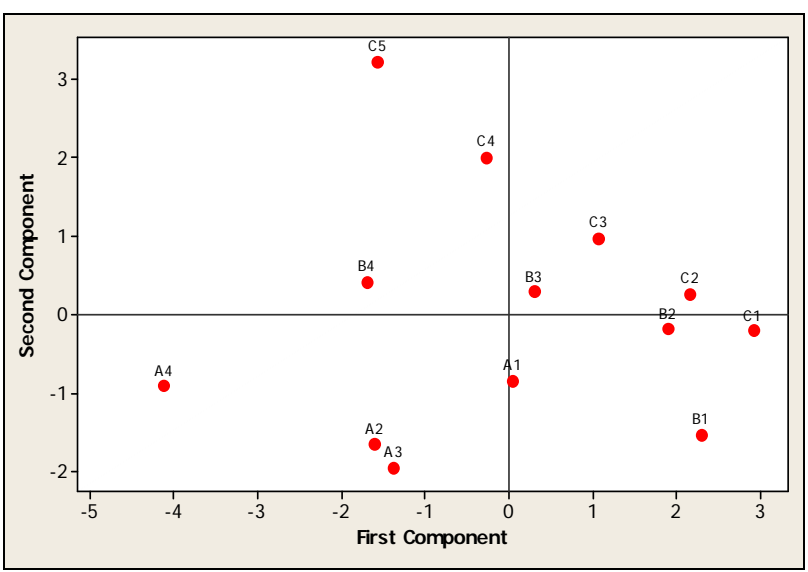

Figure 2. PC representation of individuals. 
Table 1. Person's correlation values for weight related behaviors.

\begin{tabular}{cccc}
\hline Variables (Servings per week) & Monthly income & Family norm & BMI \\
\hline Vegetables & 0.363 & 0.013 & 0.432 \\
Fruits & 0.506 & 0.032 & 0.214 \\
Bread & 0.214 & 0.034 & 0.021 \\
Milk and butter & 0.858 & 0.467 & 0.531 \\
Meat, fish & 0.867 & 0.231 & 0.671 \\
\hline
\end{tabular}

Table 2. Eigen analysis of the correlation matrix.

\begin{tabular}{ccccccc}
\hline Eigen value & 3.4732 & 1.7879 & 0.4016 & 0.1666 & 0.1249 & 0.0459 \\
\hline Cumulative proportion & 0.579 & 0.877 & 0.944 & 0.972 & 0.992 & 1.000 \\
\hline
\end{tabular}

cells and tissues in human body. Moreover, it helps to control the organs and bones in optimum working condition to provide energy. Nutrition can be easily obtained from getting a well-balanced and varied diet [15].

Therefore, the authorities should pay more attention to this matter. The findings suggest that families with low income and lower level of education may be an appropriate group to be targeted for programs on nutrition and health education.

Island wide awareness and health education programs would help to increase the nutrition levels of the low income families. Programs of this magnitude can be carried out with the cooperation of the ministry of health, ministry of education and local and foreign authorities.

\section{Acknowledgements}

The authors gratefully acknowledge the staff of Bandarawela Municipal council for their kind assistance during field work.

\section{REFERENCES}

[1] A. Eertmans, F. Baeyens and Bergh, "Food Likes and Their Relative Importance in Human Eating Behavior: Review and Preliminary Suggestions for Health Promotion," American Journal of Tropical Medicine and Hygiene, Vol. 12, No. 3, 1994, pp. 261-269.

[2] B. Caballero, L. Trugo and P. M. Finglas, "Encyclopedia of Food Sciences and Nutrition,” 2nd Edition, Academic Press, London, 2003.

[3] S. A. Bowman, S. L. Gortmaker, C. B. Ebbeling, M. A. Pereira and D. S. Ludwig, "Effect of Fast Food Consumption on Energy Intake and Diet Quality among Children in a National Household Survey," Pediatrics, Vol. 113, No. 1, 2004, pp. 111-120. doi:10.1542/peds.113.1.112

[4] C. McBride, S. Collins, C. Bell, C. Quinn and S. L. Worthy, "Parents' Influence on Children's Weight-Related Behaviors,” Research Journal for the Human Sciences,
Vol. 7, 2008.

[5] J. Kandiah, D. Brinson and V. Amend, "Compliance of a Small Convenience Sample and Efficacy of Short Term Modified Carbohydrate Diet on Weight Loss in Overweight College Students: A Pilot Study,” Food and Nutrition Sciences, Vol. 3, No. 5, 2012, pp. 699-704. doi:10.4236/fns.2012.35095

[6] Craeynest, G. Crombez, L. Haerens and I. De Bourdeaudhuij, "Do Overweight Youngsters Like Food More than Lean Peers? Assessing Their Implicit Attitudes with a Personalized Implicit Association Task. Food Quality and Preference," Science Derected-Food Quality and Preferences, Vol. 18, No. 8, 2007, pp. 1077-1084. doi:10.1016/j.foodqual.2007.05.003

[7] M. Golan, A. Weizman, A. Apter and M. Fainaru, "Parents as the Exclusive Agents of Change in the Treatment of Childhood Obesity," The American Journal of Clinical Nutrition, Vol. 67, No. 6, 1998, pp. 1130-1135.

[8] R. Brown and J. Ogden, “Children's Eating Attitudes and Behaviour: A Study of the Modeling and Control Theories of Parental Influence," Health Education Research, Vol. 19, No. 3, 2004, pp. 261-271. doi:10.1093/her/cyg040

[9] K. E. Heck and J. D Parker, "Family Structure, Socioeconomic Status, and Access to Health Care for Children," Services Research on Epidemiology, and Health Promotion, 1999.

[10] M. Y. Hood, L. L. Moore, A. Sundarajan-Ramamurti, M. Singer, L. A. Cupples and R. C. Ellison, "Parental Eating Attitudes and the Development of Obesity in Children. The Framingham Children's Study,” International Journal of Obesity, Vol. 24, No. 10, 2000, pp. 1319-1325. doi:10.1038/sj.ijo.0801396

[11] “Census Codes of Administrative Units 2011,” Uva Province, Sri Lanka, 2011, pp. 1-20.

[12] C. S. James, “Analytical Chemistry of Foods,” Mackie Academic and Professionals Ltd., Glasgow, 1996, pp. 135-148.

[13] R. M. K. T. Rathnayaka and Z.-J. Wang, "Prevalence and Effect of Personal Hygiene on Transmission of Helminthes Infection among Primary School Children Living in 
Slums," International Journal of Multidisciplinary Research, Vol. 2, No. 7, 2012, pp. 1-13.

[14] K. J. Campbell, D. A. Crawford and K. Ball, "Family Food Environment and Dietary Behaviors Likely to Promote Fatness in 5 - 6 Year Old Children," International Journal of Obesity, Vol. 30, No. 8, 2006, pp. 1272-1280. doi:10.1038/sj.ijo.0803266
[15] S. A. Bowman, S. L. Gortmaker, C. B. Ebbeling, M. A. Pereira and D. S. Ludwig, "Effect of Fast Food Consumption on Energy Intake and Diet Quality among Children in a National Household Survey," Pediatrics, Vol. 113, No. 1, 2004, pp. 111-120. doi:10.1542/peds.113.1.112 